\title{
REGULARITIES IN THE SPECTRA OF LUTECIUM
}

\author{
By William F. Meggers and Bourdon F. Scribner
}

\section{ABSTRACT}

Up to the present time no significant regularities have been found in the spectra of any of the rare earth elements, $58 \mathrm{Ce}$ to $71 \mathrm{Lu}$. A study of the arc and spark spectra of the last of these, lutecium, resulted in a separation of the lines into three distinct classes: (1) Those characterizing neutral atoms, constituting the $\mathrm{Lu}_{\mathrm{r}}$ spectrum; (2) those due to singly ionized atoms, the $\mathrm{Lu}_{11}$ spectrum; and (3) a small number of lines ascribable to doubly ionized atoms, the $\mathrm{Lu}_{11}$ spectrum. Regularities have been discovered in each of these spectra. The normal state of neutral $\mathrm{Lu}$ atoms is represented by a ${ }^{2} \mathrm{D}$ spectral term arising from the electron configuration $s^{2} d$; its levels are separated by 1993.9 wave numbers. The normal state of $\mathrm{Lu}^{+}$atoms is described by a ${ }^{1} \mathrm{~S}(s s)$, and metastable terms ${ }^{1} \mathrm{D},{ }^{3} \mathrm{D}(d s),{ }^{3} \mathrm{~F}$ $(d d)$ have also been established. A ${ }^{2} \mathrm{~S}(s)$ term describes the normal state of $\mathrm{Lu}^{++}$atoms. There is no evidence of $f$ electrons playing any part in the production of the spectra; it is concluded that the fourteen $f$ electrons in $\mathrm{Lu}$ form a closed shell of considerable stability. The structures of Lu spectra resemble those of Y more closely than those of La or Sc.

\section{CONTENTS}

I. Introduction 73

II. The spectrum of neutral $\mathrm{Lu}\left(\mathrm{Lu}_{\mathrm{r}}\right)$

III. The spectrum of singly ionized $\mathrm{Lu}\left(\mathrm{Lu}_{\mathrm{II}}\right)_{\ldots}$

IV. The spectrum of doubly ionized $\mathrm{Lu}\left(\mathrm{Lu}_{11}\right)$

V. Comparison of $21 \mathrm{Sc}, 39 \mathrm{Y}, 57 \mathrm{La}$, and $71 \mathrm{Lu}$ spectra_........ 79

\section{INTRODUCTION}

In 1927 when Hund ${ }^{1}$ summarized the results of spectral classifications and developed the theory of their relation to atomic structure, he pointed out that typical spectra have been analysed in nearly all the periods, "Nur an einer Stelle des periodischen Systems klafft eine grosse Lücke. Von den seltenen Erden ist noch kein Spektrum in Terme geordnet."

The rare earth elements are found in the sixth period; according to Bohr their appearance is explained by the assumption that the building of the shell of $5 d$ electrons beginning with $57 \mathrm{La}$ is not continued with $58 \mathrm{Ce}$, but the number of $6 s$ and $5 d$ electrons remains constant from 58 Ce to $71 \mathrm{Lu}$ while $f$ electrons are added until a shell of 14 such electrons is completed. If this shell is stable like the rare gas shells $54 \mathrm{Xe}, 36 \mathrm{Kr}$, and $18 \mathrm{~A}$, we may expect the configuration of valence electrons and, consequently, the spectral structures for $71 \mathrm{Lu}$ to resemble those of $57 \mathrm{La}, 39 \mathrm{Y}$, and $21 \mathrm{Sc}$. In any of these cases the neutral atoms in their normal states involve two $s$ and one $d$ electron $\left(s^{2} d\right)$, and the corresponding spectral term is ${ }^{2} \mathrm{D}$. The configuration

\footnotetext{
1 Hund, Linienspektren und Periodisches System der Elemente, p. 175, Julius Springer, Berlin; 1927.
} 
$d^{2} s$ is expected to yield a metastable ${ }^{4} \mathrm{~F}$ term. Singly ionized a toms of this type will exhibit, a singlet $\mathrm{S}$ term associated with the ss configuration, ${ }^{1} \mathrm{D}$ and ${ }^{3} \mathrm{D}$ terms for the $d s$ configuration and a group of terms ${ }^{1} \mathrm{~S},{ }^{1} \mathrm{D},{ }^{1} \mathrm{G},{ }^{3} \mathrm{P},{ }^{3} \mathrm{~F}$, arising from the $d d$ configuration. The normal state of doubly ionized atoms will be represented by a ${ }^{2} \mathrm{D}$ or a ${ }^{2} \mathrm{~S}$ spectral term, according as the electron is bound most firmly in a $d$ or in an $s$ orbit.

Analyses of the spectra of $\mathrm{Sc},{ }^{2} \mathrm{Y}^{3}$ and $\mathrm{La}^{4}$ have revealed all of these theoretical terms, and the temptation to look for similar terms in the spectra of Lu could not be resisted. It was first necessary, however, to make new descriptions of the spectra, since the older data were too incomplete and unreliable. The authors have photographed both arc and spark spectra of $\mathrm{Lu}$ in the wave length interval 2,000 $\mathrm{A}$ to $9,000 \mathrm{~A}$, and have succeeded in separating the $\mathrm{Lu}_{\mathrm{I}}, \mathrm{Lu}_{\mathrm{II}}$, and $\mathrm{Lu}_{\mathrm{In}}$ lines characteristic of neutral, singly ionized and doubly ionized atoms, respectively. Complete wave-length data and more extensive classification of the spectral lines will be presented in a subsequent paper. The main object of this paper is to describe and interpret certain regularities which have been discovered among the most prominent lines of the Lu spectra. We shall here retain the notation used for similar spectra cited above.

The arc spectrum of $\mathrm{Lu}$ was excited in a 220 -volt direct-current arc between silver electrodes on which some Lu salt was fused. The same electrodes were then used in a condensed high-voltage discharge to excite the spark spectra. Both spectra were photographed on the same plate, and comparison of line intensities in the two sources made it easy to recognize the lines belonging to neutral and to ionized atoms. The lines of neutral Lu atoms are strongly developed in the arc, but are very weak in the spark. A small number of lines (about 50) occur with considerable intensity in the arc but, for the most part, somewhat enhanced in the spark. These are recognized as the lines involving the normal or metastable states of the singly ionized atoms. A larger number of lines appear only in the spark or greatly enhanced in this source when compared with the arc. These lines are usually somewhat hazy and unsymmetrical. They undoubtedly involve higher excited states in the ionized atoms. Within the range of the observations five lines are recognized as belonging to doubly ionized Lu atoms because they are strong in the spark, but are not excited at all in the 220-volt arc except near the negative electrode. In general, the properties of the Lu spectral lines closely parallel those of $\mathrm{Y}$ and La lines which have been studied in similar sources. Perhaps the most striking difference is the relatively greater simplicity of the Lu spectra. The number of strong lines in the $\mathrm{Lu}_{\mathrm{I}}$ spectrum does not exceed 50, and, roughly, the same number of intense lines appear in the $\mathrm{Lu}_{11}$ spectrum, while in the corresponding $Y_{I I}$ and $L a_{I I}$ spectra the numbers are much larger. The reasons for this difference will be discussed after the Lu regularities are exhibited.

It must be remembered that wave lengths and estimated relative intensities are the only data at hand for the analysis of Lu spectra,

${ }_{2}$ Russell and Meggers, B. S. Sci. Paper No. 558, 22, p. 329; 1927.

a Meggers and Russell, B. S. Jour. Research, 2 (RP 55), p. 733; 1929.

1 Meggers, J. Wash. Acad. Sci., 17, p. 25; 1927. J. Opt. Soc. Am., 14, p. 191; 1927; and extensive unpublished results. 
no observations of Zeeman effects, temperature classes, absorption or reversal, and pressure effect have ever been made. The situation is similar to that which existed for Hf spectra,${ }^{5}$ so that the method of analysis which was used there was applied here. It consists, briefly, in systematically subtracting the wave numbers of groups of lines which are likely to be related, extending as far as possible a twodimensional wave-number system representing combinations of spectral terms, and attempting to interpret the spectral terms on the basis of quantum theory. The combination principle, and the wellknown rules governing quantum numbers, line intensities, and spectral-term intervals, make it possible to analyze any spectrum, provided that one has a reasonably good description of the spectrum.

\section{THE SPECTRUM OF NEUTRAL Lu $\left(\mathrm{Lu}_{\mathrm{I}}\right)$}

A half hundred of the most prominent arc lines of Lu were selected and the vacuum wave numbers were systematically subtracted from each other up to differences of $15,000 \mathrm{~cm}^{-1}$. When these were tabulated it was seen that the only difference which occurred more than three times was $1,993.9 \mathrm{~cm}^{-1}$ which repeated 10 times, and must, therefore, be regarded as significant. This is regarded as the separation of ${ }^{2} \mathrm{D}_{2}$ and ${ }^{2} \mathrm{D}_{3}$, the two sublevels of the ${ }^{2} \mathrm{D}$ term describing the normal state of neutral Lu atoms. Combinations of this term with higher excited states are presented in Table 1, where the level combinations are represented by vacuum wave numbers, above which the measured wave length in air and estimated intensities are given. Two intensity numbers appear in parentheses after each wave length, the first is the intensity in the arc and the second the intensity in the spark. These numbers show that the lines are a homogeneous group, easily excited in the arc where a large percentage of atoms are neutral, but weak in the spark where most of the atoms are ionized. Guided by relative intensities and by reasonable level separations we have hazarded an identification of many of the excited states, but these term symbols are subject to correction. It is especially difficult to select the single combinations with any certainty, but it may be added that the only strong lines of the $\mathrm{Lu}_{\mathrm{I}}$ spectrum not included in Table 1, are the following: $3,647.77$ (50, 5), 4,518.58 $(200,40), 5,001.15(100,20)$.

Some of the unidentified levels may represent doublet-quartet intercombinations, but we have not succeeded as yet in completing any quartet multiplets. The metastable ${ }^{4} \mathrm{~F}\left(d^{2} s\right)$ term is expected to be rather high in the energy diagram and its combinations are likely to consist mostly of weaker lines.

s Meggers and Scribner, J. Opt. Soc. Am., 17, p. 83; 1928. B. S. Jour. Research, 4 (RP 139), p. $169 ; 1930$. 
TABLE 1.-Multiplets in the Lu spectrum

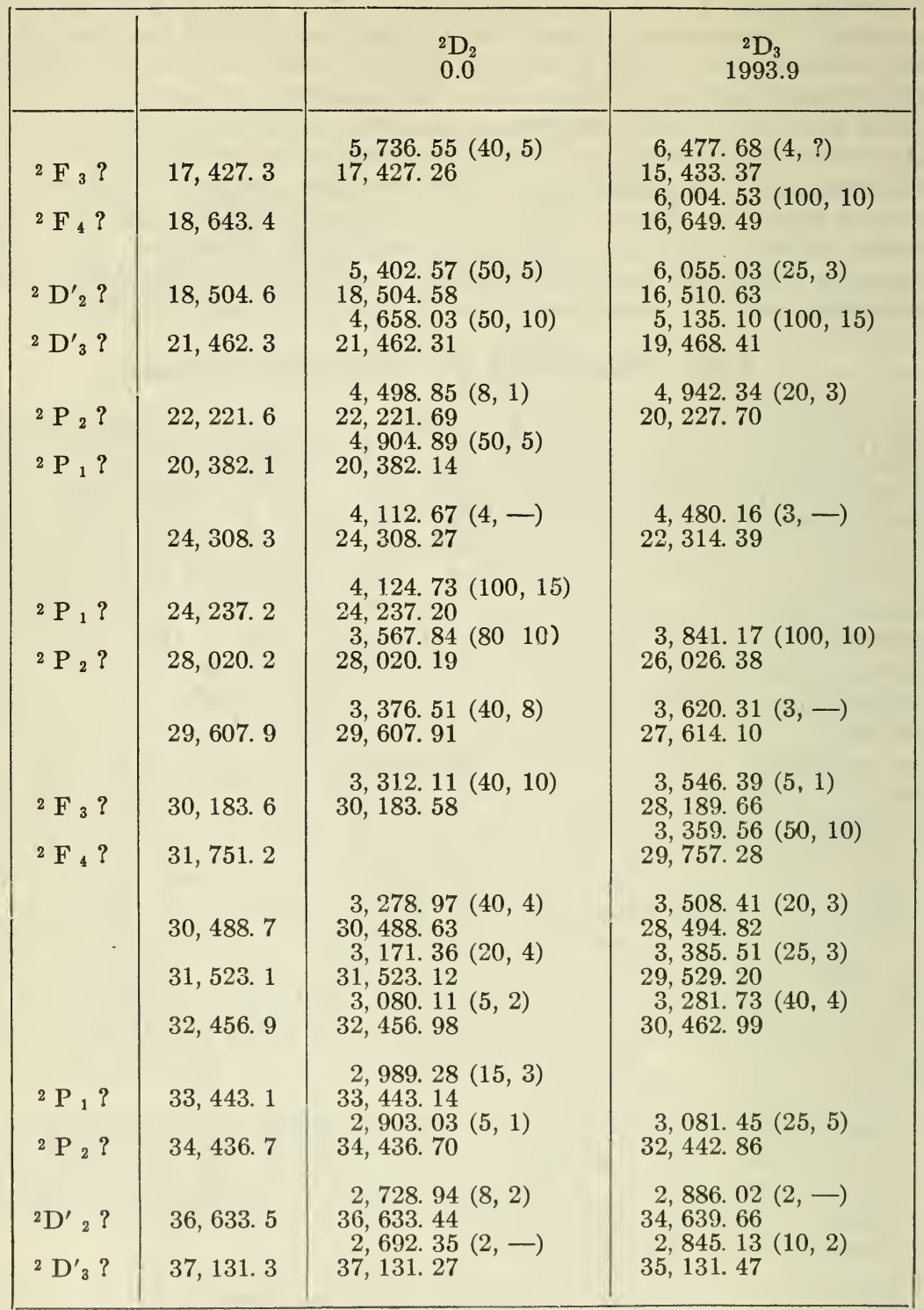




\section{THE SPECTRUM OF SINGLY IONIZED $\mathrm{Lu}\left(\mathrm{Lu}_{\mathrm{II}}\right)$}

After selecting about 50 of the more intense spark lines (also strong in the arc) the corresponding vacuum wave numbers were systematically substracted, and three recurring differences (639.1, 1,763.8, $3,133.5$ ) were at once recognized. These formed the nucleus of a wave-number system which was finally extended to that shown in Table 2. The structure of this table is similar to that of Table 1. The spectral term combinations are represented by vacuum wave numbers appearing directly below the observed wave lengths in air. The wave lengths are followed by arc and spark intensities in parentheses. Lines marked $d$ are double or complex with hyperfine structure, and a few marked $l$ are shaded to longer wave lengths. The latter involve rather high levels and begin to partake of the general character of lines which are more difficult to excite. The easily excited lines, such as $a^{3} \mathrm{D}-a^{3} \mathrm{P}$, appear with about equal intensity in arc and spark, but, in general, the other lines show increasing enhancement in the latter source as the values of the energy levels increase. Assuming that the three lines, $2,195.55,2,615.43$, and $3,507.39$, arise from combinations of a ${ }^{1} \mathrm{~S}_{0}$ term with levels having inner quantum number $j=1$, the inner quantum numbers of the remaining levels are determined from their combinations, and the levels are then grouped into terms. The combinations, intensities, and intervals have made it possible to identify all of the levels, and there can hardly be any question as to the correctness of the interpretation. Table 2 contains a homogeneous group of lines and practically all of the lines of this character. All of the expected terms of low energy content have been established except $b^{1} \mathrm{~S}, b^{1} \mathrm{D}, a^{1} \mathrm{G}$, and $a^{3} \mathrm{P}^{\prime}$, which are probably so high in the energy diagram that their principal combinations lie far out in the infra-red. 


\begin{tabular}{|c|c|c|c|c|c|c|c|c|c|}
\hline 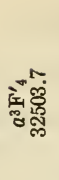 & & & & & & 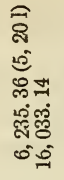 & 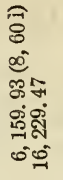 & & 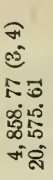 \\
\hline 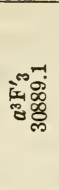 & & & 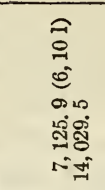 & & 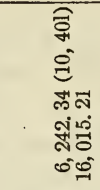 & 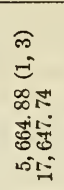 & 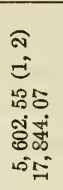 & 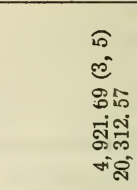 & 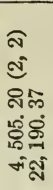 \\
\hline 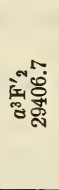 & & & 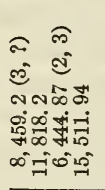 & 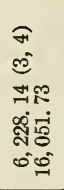 & 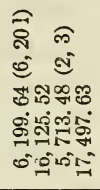 & & & 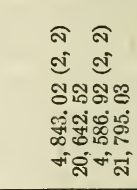 & 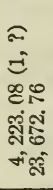 \\
\hline 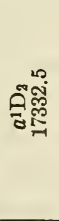 & 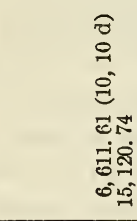 & 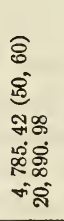 & 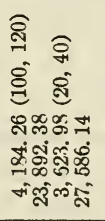 & 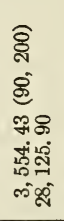 & & & 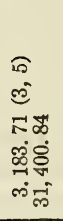 & 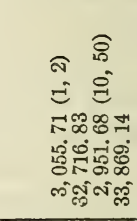 & 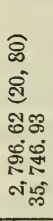 \\
\hline 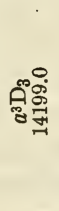 & 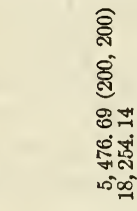 & & 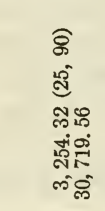 & 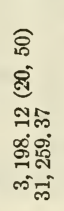 & 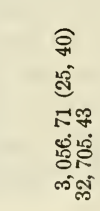 & 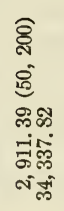 & 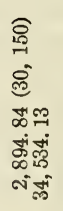 & 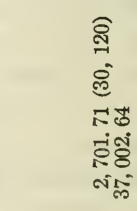 & 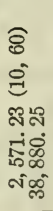 \\
\hline 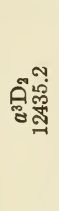 & 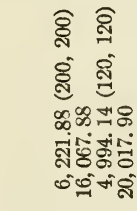 & 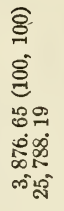 & 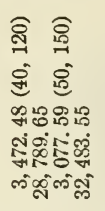 & 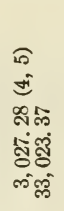 & 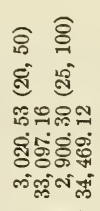 & & 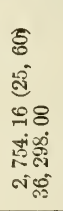 & 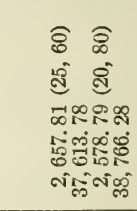 & 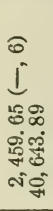 \\
\hline 兽兽 & 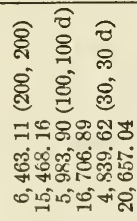 & & 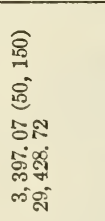 & 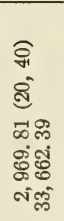 & 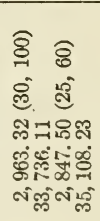 & & & 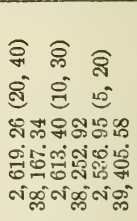 & \\
\hline 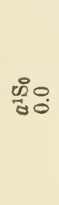 & 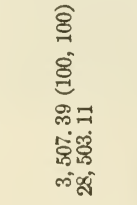 & 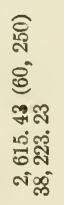 & & & 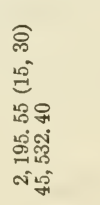 & & & & \\
\hline & 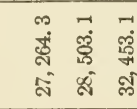 & $\begin{array}{l}\text { ๙ } \\
\text { ฌू } \\
\infty \\
\infty\end{array}$ & $\begin{array}{l}\infty \\
\dot{\mathbb{N}} \\
\stackrel{\infty}{\sigma} \\
\vec{\forall} \\
\overrightarrow{+}\end{array}$ & 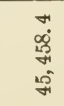 & 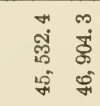 & 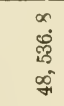 & 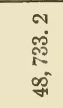 & 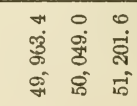 & 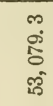 \\
\hline & 密芯 & $\vec{a}$ & 番悉 & อ̈ & 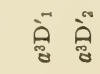 & 宽 & ڤొ & 点 今 & 䜿 \\
\hline
\end{tabular}




\section{THE SPECTRUM OF DOUBLY IONIZED Lu $\left(\mathrm{Lu}_{\mathrm{III}}\right)$}

Within the range of our observations five lines undoubtedly belonging to $\mathrm{Lu}^{++}$atoms have been recorded. These lines are grouped in multiplets in Table 3, where an interpretation of the combining levels is given. The letter $e$ after an arc intensity signifies that the line appeared only at the negative electrode. Two of the lines clearly show evidence of being afflicted with hyperfine structure.

TABLE 3.-Multiplets in the Lu $u_{11}$ spectrum

\begin{tabular}{|c|c|c|c|}
\hline & $\begin{array}{l}{ }^{2} \mathrm{~S}_{1} \\
0.0\end{array}$ & $\begin{array}{l}{ }^{2} \mathrm{D}_{2} \\
6304.3\end{array}$ & $\begin{array}{c}{ }^{2} \mathrm{D}_{3} \\
8648.1\end{array}$ \\
\hline $\begin{array}{l}{ }^{2} \mathrm{P}_{1} \\
3,8997.0 \\
{ }_{2} \mathrm{P}_{2} \\
4,4705.0\end{array}$ & $\begin{array}{c}2,563.53(1 e, 50) \\
38,997.0 \\
2,236.19(3 e d, 100) \\
44,705.0\end{array}$ & $\begin{array}{c}3,057.90(3 e, 100) \\
32,692.7 \\
2,603.34(5 e d, 200) \\
38,400.7\end{array}$ & $\begin{array}{l}2,772.58(4 e, 125) \\
36,056.9\end{array}$ \\
\hline
\end{tabular}

The arrangement and interpretation of these $\mathrm{Lu}_{\mathrm{III}}$ regularities may, perhaps, be questioned because of the abnormally large intensity of of $2,603.34 \mathrm{~A}\left({ }^{2} \mathrm{D}_{2}-{ }^{2} \mathrm{P}_{2}\right)$, but the only other possibility is to interchange ${ }^{2} \mathrm{~S}_{1}$ and ${ }^{2} \mathrm{D}_{2}$ which would make the separation of ${ }^{2} \mathrm{D}$ abnormally large. We hope to be able, ultimately, to confirm these terms with other combinations and more definitive intensities.

\section{COMPARISON OF $21 \mathrm{Sc}, 39$ Y, 57 La AND 71 Lu SPECTRA}

The lowest energy (normal state) in any atom with 3 -valence electrons $s^{2} d$ is represented by a ${ }^{2} \mathrm{D}$ spectral term and such a term has been found in every case. These terms for $\mathrm{Sc}_{\mathrm{I}}, \mathrm{Y}_{\mathrm{I}}, \mathrm{La}_{\mathrm{I}}$, and $\mathrm{Lu}_{\mathrm{r}}$ spectra are collected in Table 4. A more or less regular increase in the separation of the ${ }^{2} \mathrm{D}$ levels accompanies the atomic number.

TABLE 4.-Comparison of $\left(s^{2} d\right){ }^{2} D$ terms in $S c_{1}, Y_{1}, L a_{1}$, and Lu spectra

\begin{tabular}{|c|c|r|c|c|}
\hline Levels & $\mathrm{Sc}_{1}$ & $\mathrm{Y}_{\mathrm{I}}$ & $\mathrm{La}_{\mathrm{I}}$ & $\mathrm{Iu}_{\mathrm{I}}$ \\
\hline${ }^{2} \mathrm{D}_{2}$ & $\begin{array}{r}0.0 \\
{ }^{2} \mathrm{D}_{3}\end{array}$ & $\begin{array}{r}0.0 \\
530.5\end{array}$ & $\begin{array}{r}0.0 \\
1,053.2\end{array}$ & $\begin{array}{r}0.0 \\
1,993.9\end{array}$ \\
\hline
\end{tabular}

In order to compare the analogous first spark spectra of these four elements the relative terms for $s s$, $d d$, and $d s$ electron configurations are collected in Table 5. There is a close resemblance between $Y_{I I}$ and $\mathrm{Lu}_{\mathrm{rI}}$ in the relative positions of the various terms, except that the separations in the latter case are much larger and the ${ }^{3} \mathrm{~F}^{\prime}$ term has reached a considerable altitude in the energy diagram. If this parallelism can be extended to the undiscovered terms ${ }^{1} \mathrm{D},{ }^{1} \mathrm{G}$, and ${ }^{3} \mathrm{P}^{\prime}$ they will be much higher and difficult to establish.

In the $\mathrm{La}_{\mathrm{II}}$ spectrum the following additional middle terms have been found: $(s f)^{1} \mathrm{~F},{ }^{3} \mathrm{~F},(d f){ }^{1} \mathrm{P},{ }^{1} \mathrm{D}^{\prime},{ }^{1} \mathrm{~F},{ }^{1} \mathrm{G}^{\prime},{ }^{1} \mathrm{H},{ }^{3} \mathrm{P},{ }^{3} \mathrm{D}^{\prime},{ }^{3} \mathrm{~F},{ }^{3} \mathrm{G}^{\prime},{ }^{3} \mathrm{H}$. No evidence of these terms has been found in any of the other spectra;

$115233^{\circ}-30-6$ 
their presence in La accounts for the relatively greater complexity of the $\mathrm{La}_{\mathrm{II}}$ spectrum. $57 \mathrm{La}$ is the last element just preceding the rare earths, $58 \mathrm{Ce}-71 \mathrm{Lu}$, in which $f$-type electrons are added, and it appears that this feature of atom building is anticipated in $\mathrm{La}^{+}$so that in the excited state either a $d$ or an $s$ electron may occupy $f$-type orbits. The fact that $s f$ and $d f$ terms do not appear in the $\mathrm{Lu}_{\mathrm{II}}$ spectrum is evidence that the completed group of fourteen $f$ electrons is a closed shell of considerable stability resembling the rare gas shells. TABLE 5.-Comparison of $(s s),(d d)$, and (ds) terms in $S c_{\mathrm{II}}, Y_{\mathrm{II}}, L a_{\mathrm{II}}$, and $L u_{\mathrm{II}}$

\begin{tabular}{|c|c|c|c|c|c|}
\hline $\begin{array}{l}\text { Elec- } \\
\text { trons }\end{array}$ & Levels & $S c_{I I}$ & $Y_{I I}$ & $\mathrm{La}_{11}$ & $\mathrm{Lu}_{\mathrm{II}}$ \\
\hline $\begin{array}{l}s s \\
d d\end{array}$ & $\begin{array}{l}{ }^{1} \mathrm{~S}_{0} \\
{ }^{1} \mathrm{D}_{2} \\
{ }^{1} \mathrm{G}_{4} \\
{ }^{3} \mathrm{P}^{\prime}{ }_{0} \\
{ }^{3} \mathrm{P}^{\prime}{ }_{1}\end{array}$ & $\begin{array}{l}11,736.4 \\
10,944.5 \\
14,261.4 \\
12,074.0 \\
12,101.4\end{array}$ & $\begin{array}{r}0.0 \\
14,832.9 \\
15,683.0 \\
13,883.5 \\
14,018.3\end{array}$ & $\begin{array}{r}7,394.6 \\
10,094.9 \\
7,473.4 \\
5,249.8 \\
5,718.2\end{array}$ & 0. 0 \\
\hline & $\begin{array}{l}{ }^{8} \mathrm{P}^{\prime}{ }^{2} \\
{ }^{3} \mathrm{~F}^{\prime}{ }^{2} \\
{ }^{3} \mathrm{~F}^{\prime}{ }^{2} \\
{ }^{3} \mathrm{~F}^{\prime}{ }_{4}\end{array}$ & $\begin{array}{r}12,154.3 \\
4,802.8 \\
4,883.4 \\
4,987.6\end{array}$ & $\begin{array}{r}14,098.2 \\
8,003.1 \\
8,328.0 \\
8,743.4\end{array}$ & $\begin{array}{r}6,227.5 \\
0.0 \\
1,016.0 \\
1,970.8\end{array}$ & $\begin{array}{l}29,406.7 \\
30,889.1 \\
32,503.7\end{array}$ \\
\hline$d s$ & $\begin{array}{l}{ }^{1} \mathrm{D}_{2} \\
{ }^{3} \mathrm{D}_{1} \\
{ }^{3} \mathrm{D}_{2} \\
{ }^{3} \mathrm{D}_{3}\end{array}$ & $\begin{array}{r}2,541.0 \\
0.0 \\
67.7 \\
177.6\end{array}$ & $\begin{array}{r}3,296.3 \\
840.2 \\
1,045.1 \\
1,449.9\end{array}$ & $\begin{array}{l}1,394.5 \\
1,895.1 \\
2,591.6 \\
3,250.4\end{array}$ & $\begin{array}{l}17,332.5 \\
11,796.1 \\
12,435.2 \\
14,199.0\end{array}$ \\
\hline
\end{tabular}

Terms of the analogous second spark spectra of these four elements are collected for comparison in Table 6.

TABLE 6.-Comparison of $d, s$, and $p$ terms in $S c_{I I I}, Y_{I I I}, L a_{I I I}$, and $L u_{I I I}$ spectra

\begin{tabular}{|c|c|c|c|c|c|}
\hline Electron & Levels & $\mathrm{Sc}_{\mathrm{III}}$ & $Y_{\text {III }}$ & $\mathrm{La}_{\mathrm{III}}$ & $\mathrm{Lu}_{\mathrm{III}}$ \\
\hline $\begin{array}{l}s \\
p\end{array}$ & $\begin{array}{l}{ }^{2} \mathrm{D}_{2} \\
{ }^{2} \mathrm{D}_{3} \\
{ }^{2} \mathrm{~S}_{1} \\
{ }^{2} \mathrm{P}_{1} \\
{ }^{2} \mathrm{P}_{2}\end{array}$ & $\begin{array}{r}0 \\
198 \\
25,537 \\
62,102 \\
62,576\end{array}$ & $\begin{array}{r}0.0 \\
724.8 \\
7,466.2 \\
41,401.2 \\
42,954.7\end{array}$ & $\begin{array}{r}0.0 \\
1,603.2 \\
13,590.8 \\
42,014.9 \\
45,110.6\end{array}$ & $\begin{array}{r}6,304.3 \\
8,648.1 \\
0.0 \\
38,997.0 \\
44,705 .\end{array}$ \\
\hline
\end{tabular}

If our interpretation of the $\mathrm{Lu}_{\mathrm{II}}$ lines is correct it supports other evidence that in the period of $5 d$ and $6 s$ electrons the latter become more stable than the former. Attention is called to the fact that the (ss) ${ }^{1} \mathrm{~S}$ terms of the first spark spectra (Table 5) show a trend very much like that of the $(s){ }^{2} \mathrm{~S}$ terms of the second spark spectra, being highest for Sc, considerably lower for La, and lowest for $\mathrm{Y}$ and $\mathrm{Lu}$. The relatively small advantage of ${ }^{2} \mathrm{~S}$ over ${ }^{2} \mathrm{D}$ in the $\mathrm{Lu}_{\text {III }}$ spectrum appears to account for the decided advantage of ${ }^{1} \mathrm{~S}$ over ${ }^{3} \mathrm{D}$ as the lowest term in the $\mathrm{Lu}_{\text {II }}$ spectrum. 
Finally, it will be of interest to compare the total intervals of related D terms of three successive spectra for each of the four elements discussed above. These are presented in Table 7.

TABLE 7.-Total separation of lowest $D$ levels in successive spectra of Sc, $Y, L a$, and $L u$

\begin{tabular}{|c|c|c|c|c|c|}
\hline Spectrum & $\begin{array}{l}\text { Level sepa- } \\
\text { ration }\end{array}$ & $\mathrm{Sc}$ & $\mathrm{Y}$ & $\mathrm{La}$ & $\mathrm{Lu}$ \\
\hline $\begin{array}{l}\mathrm{I}_{-}-. . \\
\mathrm{II}_{-} \\
\text {III }\end{array}$ & $\begin{array}{l}{ }^{2} \mathrm{D}_{2}-{ }^{2} \mathrm{D}_{3} \\
{ }^{3} \mathrm{D}_{1}-{ }^{3} \mathrm{D}_{3} \\
{ }^{2} \mathrm{D}_{2}-{ }^{2} \mathrm{D}_{3}\end{array}$ & $\begin{array}{l}168.3 \\
177.6 \\
198.0\end{array}$ & $\begin{array}{l}530.5 \\
609.7 \\
724.8\end{array}$ & $\begin{array}{l}1,053.2 \\
1,355.3 \\
1,603.2\end{array}$ & $\begin{array}{l}1,993.9 \\
2,402.9 \\
2,343.8\end{array}$ \\
\hline
\end{tabular}

The three successive D terms for each element are intimately connected according to the theory of series convergence to limits, and the total separations should be the same (to a first approximation) for the successive spectra of each element. The reality of this connection is obvious from the data in Table 7, and this may be regarded as a general verification of the term identifications and analyses of the Sc, Y, La, and Lu spectra.

Washington, March 7, 1930. 